\title{
Individualized 3D scanning and printing for non-melanoma skin cancer brachytherapy: a financial study for its integration into clinical workflow
}

\author{
Meritxell Arenas, MD, PhD', Sebastià Sabater, MD, PhD², Andreu Sintas, BA³, Monica Arguís, MD!, \\ Victor Hernández, MD, PhD4, Miguel Árquez, MD', lolanda López, MD', Àngeles Rovirosa, MD, PhD 5 , \\ Doménec Puig, MD, PhD ${ }^{3}$ \\ 'Radiation Oncology Department, Hospital Universitari Sant Joan de Reus, Institut d'Investigacions Sanitàries Pere Virgili, Universitat \\ Rovira i Virgili, Tarragona, ${ }^{2}$ Radiation Oncology Department, Complejo Hospitalario Universitario de Albacete, ${ }^{3}$ Department of Computer \\ Engineering and Mathematics, Universitat Rovira i Virgili, Tarragona, ${ }^{4}$ Department of Medical Physics, Hospital Universitari Sant Joan de \\ Reus, Institut d'Investigacions Sanitàries Pere Virgili, Universitat Rovira i Virgili, Tarragona, ${ }^{5}$ Radiation Oncology Department, Hospital Clinic, \\ Barcelona, Spain
}

\begin{abstract}
Purpose: Skin cancer is the most common tumor in the population. There are different therapeutic modalities. Brachytherapy is one of the techniques used, in which it is necessary to build customized moulds for some patients. Currently, these moulds are made by hand using rudimentary techniques. We present a new procedure based on 3D printing and the analysis of the clinical workflow.

Material and methods: Moulds can be made either by hand or by automated 3D printing. For making moulds by hand, a patient's alginate negative is created and, from that, the gypsum cast and customized moulds are made by hand from the patient's negative template. The new process is based on 3D printing. The first step is to take a 3D scan of the surface of the patient and then, 3D modelling software is used to obtain an accurate anatomical reconstruction of the treatment area. We present the clinical workflow using 3D scanning and printing technology, comparing its costs with the usual custom handmade mould protocol.

Results: The time spent for the new process is 6.25 hours, in contrast to the time spent for the conventional process, which is 9.5 hours. We found a $34 \%$ reduction in time required to create a mould for brachytherapy treatment. The labor cost of the conventional process is 211.5 vs. 152.5 hours, so the reduction is 59 hours. There is also a $49.5 \%$ reduction in the financial costs, mostly due to lack of need of a computed tomography (CT) scan of the gypsum and the mould. 3D scanning and printing offers financial benefits and reduces the clinical workload.

Conclusions: As the present project demonstrates, through the application of 3D printing technologies, the costs and time spent during the process in the clinical workload in brachytherapy treatment are reduced. Overall, 3D printing is a promising technique for brachytherapy that might be well received in the community.

J Contemp Brachytherapy 2017; 9, 3: 270-276 DOI: https://doi.org/10.5114/jcb.2017.68134
\end{abstract}

Key words: 3D printing, brachytherapy, moulds, skin cancer.

\section{Purpose}

New radiotherapy techniques are emerging that will improve treatment planning and delivery. One of those is the use of 3D printing technology, which is being utilized more frequently in medicine more each year $[1,2,3]$. In radiotherapy, 3D printing has been introduced to create boluses $[4,5,6,7,8,9]$, phantoms for quality assurance $[10,11$, $12,13]$, compensator blocks [14], proton range compensators [15], and tools for brachytherapy [16,17,18,19,20,21,22]. Skin cancer is currently one of the most common tumors
$[23,24]$. One radiotherapy technique used in treatment is high-dose-rate brachytherapy, which involves making individualized moulds [25]. A mould of such precise characteristics must be made perfectly adapted to the patient's anatomy, which is expensive (especially in terms of personnel) and causes patient discomfort.

Our study analyses the clinical workflow using 3D scanning and printing technology, and comparing its costs with the usual custom handmade mould protocol. 


\section{Material and methods}

One of the most important aspects of treatment planning for skin cancer is defining the target volume. In brachytherapy, customized moulds are indicated in those cases where the tumors are located in irregular anatomical areas, and a perfect match between the mould and the skin is essential. Moulds can be made either by hand (Figure 1) or by automated 3D printing (Figure 2).

\section{Making moulds by hand}

The patient's alginate negative is created and, from that, the gypsum cast is also made. The gypsum takes about 24 hours to dry, and then the treatment area is defined.
Customized moulds are made by hand from the patient's negative template and different wax layers are added to place the catheter tubes between them (Figure 3A). Next, a computed tomography (CT) scan of the gypsum and the mould is taken to confirm the suitability of the mould. If everything is correct, another CT scan is taken with the mould located on the patient. Finally, the radiation oncologist delineates the target volume and organs at risk, and treatment planning is carried out.

\section{The new process based on $3 D$ printing}

The use of a 3D surface scanner (Sense Scanner from 3D Systems (Rock Hill, SC, USA), 480 euros), a 3D printer
1

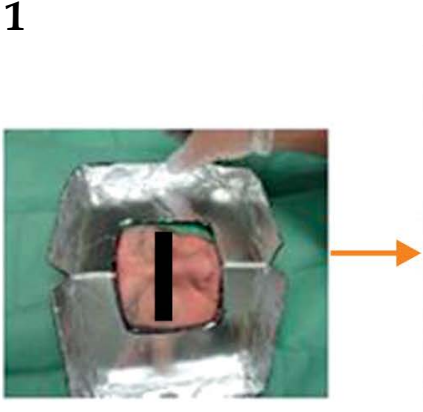

5
2

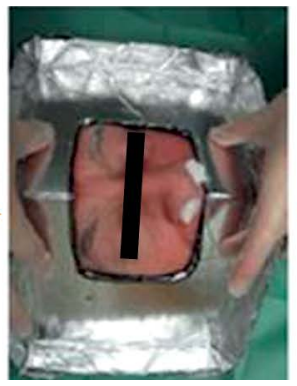

6
3

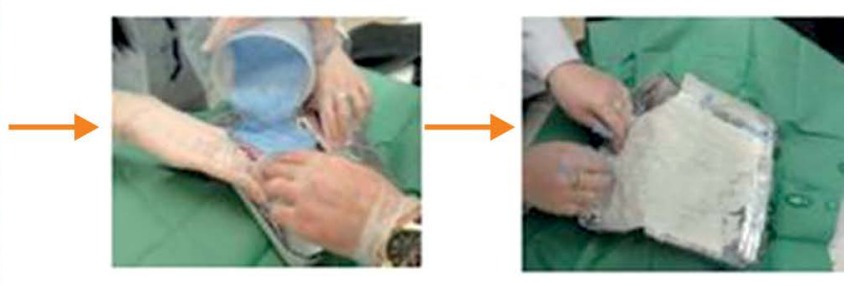

7

4

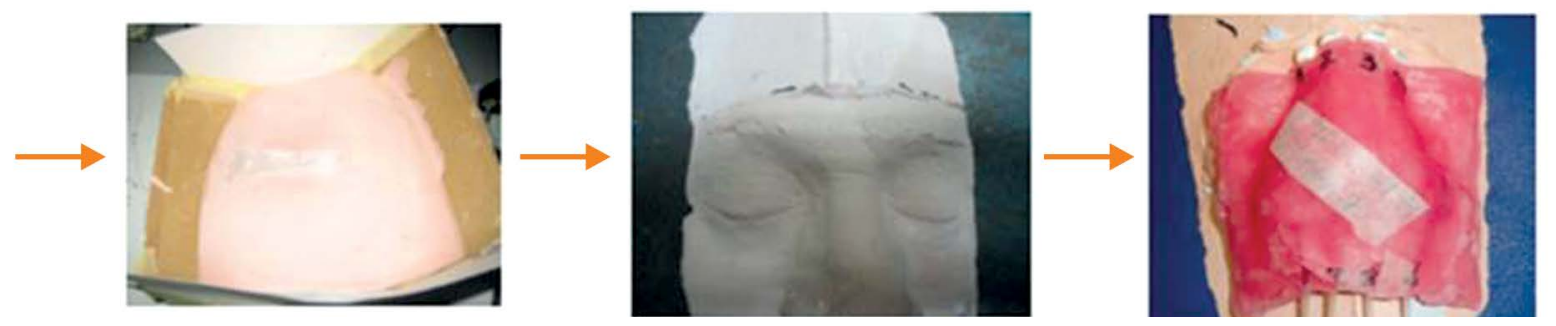

Fig. 1. Process of creating, by hand, a personalized mould for the treatment of a cutaneous cancer. 1, 2- delimitation of the treatment zone, patient protection; 3, 4 - applying the plaster on wax for the negative mould of the treatment area; 5, 6 - drying and developing the treatment area; 7 - assembly of the multilayer application

1

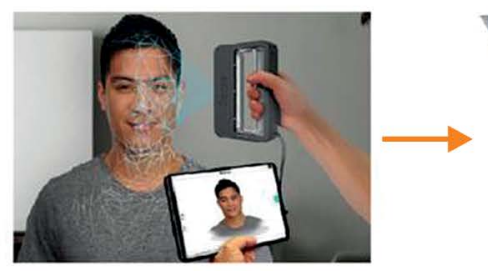

5

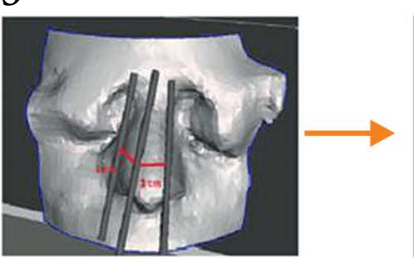

2

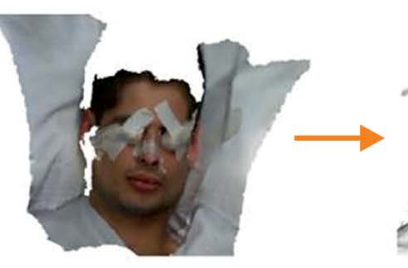

6

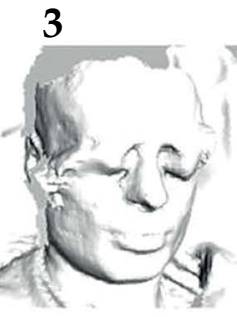

7

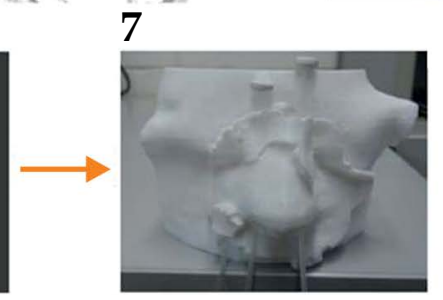

Fig. 2. Process of creating, by 3D printing, a personalized mould for the treatment of a cutaneous cancer. $1-3 \mathrm{D}$ scan of the patient; 2, 3, 4 - model of the patient and delimitation of the treatment zone (lesion in the right nasal area); 5 - creation and placement of the markers for the catheters; 6 - creation of a surface and minimum depth in the model that will be printed; 7 - mould after printing 

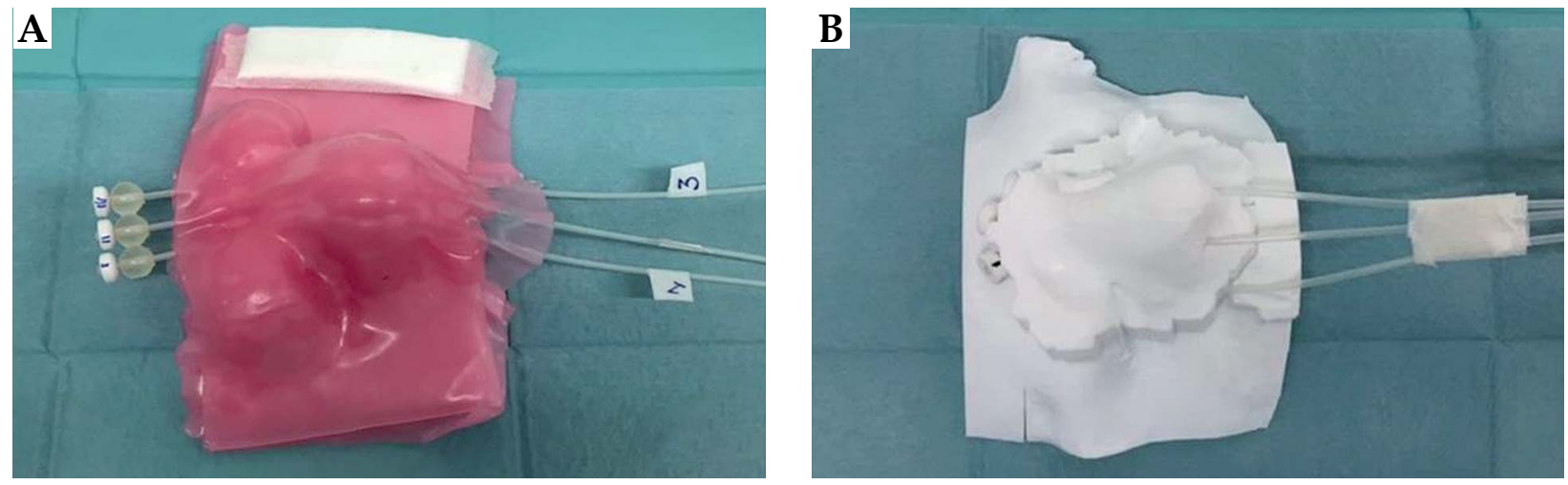

Figure 3. A) Customized mould for treating skin cancer made by conventional process; B) 3D printed mould made with novel process

(BCN3D Sigma, from BCN3D Technologies, Castelldefels, Barcelona, Spain, 2300 euros) and 3D modeling software (MeshMixer, Opensource) radically changes the process. The first step is to take a 3D scan of the surface of patient. The resultant image is an accurate anatomical reconstruction of the treatment area. Then, 3D modelling software is used to completely adapt the model to the particular anatomy of a patient, adding the required depth and marking cylindrical spaces for placing the catheters, which can be located accurately at least $5 \mathrm{~mm}$ above the skin and $1 \mathrm{~cm}$ from each other (Figure 3B), which is the configuration needed for the treatment. The final step is to take a CT scan of the $3 \mathrm{D}$ printed mould on the patient, thus avoiding the need for a CT scan of the gypsum and the mould. The area that we want to treat is delineated and the dosimetry is carried out, similar to the conventional procedure.

Table 1 shows the times that were estimated from mean times obtained in typical clinical procedures. Labor costs were calculated taking into account the hourly cost of the radiation oncologist, physicist, and radiation therapist, according to hospital salary tables (radiation oncologist and physicist: 38 euros per hour; radiation therapist: 15 euros per hour).

\section{Results}

Table 1 shows the labor and material costs comparison between the two processes. The time spent on the new process is 6.25 hours, in contrast to the time spent on the conventional process, which is 9.5 hours, so we found a $34 \%$ reduction in the time taken to make the mould for brachytherapy treatment (not considering the time in which the mould is being printed, as it requires no human attention). The labor cost of the conventional process is 211.5 vs. 152.5 hours, therefore the reduction is 59 hours. There is also a $49.5 \%$ reduction in the financial costs, mostly due to no need of a CT scan of the gypsum and the mould. 3D printing technology would also greatly reduce the time spent creating brachytherapy moulds, with the waiting time reduced by $57 \%$ due to the gypsum taking 24 hours to dry. This will create huge benefits for the patients, as they would be able to start the dosimetry treatment sooner and reduce the time spent in the hospital by 45 minutes ( 2 hours for conventional vs. 11/4 hours for $3 \mathrm{D}$ printing). The new process also reduces the discomfort caused when creating the negative and the gypsum moulds, which are particularly uncomfortable steps in the conventional process.

Table 2 shows the analysis of the cost of 3D printing a mould of a patient, printed at $90 \%$ infill and weighing 94 gram (thus requiring 7 hours working time). This is the typical configuration when printing a mould from a facial skin lesion patient. The 3D printer price includes the start-up cost, maintenance, and reliability costs. We have calculated costs based on 60 patients per year, therefore 7 hours per patient represents 2,520 hours of working time over a 6 year period, which can be estimated as a minimum working time for the printer. The initial investment needed to acquire this new $3 \mathrm{D}$ printing technology are around 480 euros for the scanner and 1,800-2,300 euros for the printer. The printer used in this study cost 2,300 euros, as it has a dual-extruder function; however, printers without this functionality, which cost less, around 1,800 euros, are capable of the same workflow. A cost reduction is therefore evident and would be even greater in centers with larger number of patients.

\section{Discussion}

Radiation therapy is an effective treatment for skin cancer. Several techniques can be used, such as superficial X-rays, orthovoltage X-rays, megavoltage photons, electron beam irradiation, and brachytherapy. Radiotherapy is continuing to introduce new technologies into the workflow, like magnetic resonance imaging (MRI) [1], and devices that come from other fields of the science, like the surface scanners and 3D-printers. Skin cancer brachytherapy treatment can be carried out using interstitial or plesiotherapy techniques $[26,27,28,29,30,31]$. High-dose-rate electronic brachytherapy using surface applicators for the treatment of non-melanoma skin carcinoma is a relatively new technique $[32,33]$. Plesiotherapy can be delivered by fixed applicators for treating small tumors in flat areas or by customized moulds that adapt radiation doses to very uneven surfaces without the need to shield surrounding areas. We have presented a new process for creating moulds based on 3D printing, and a financial study for its integration into the clinical workflow. 


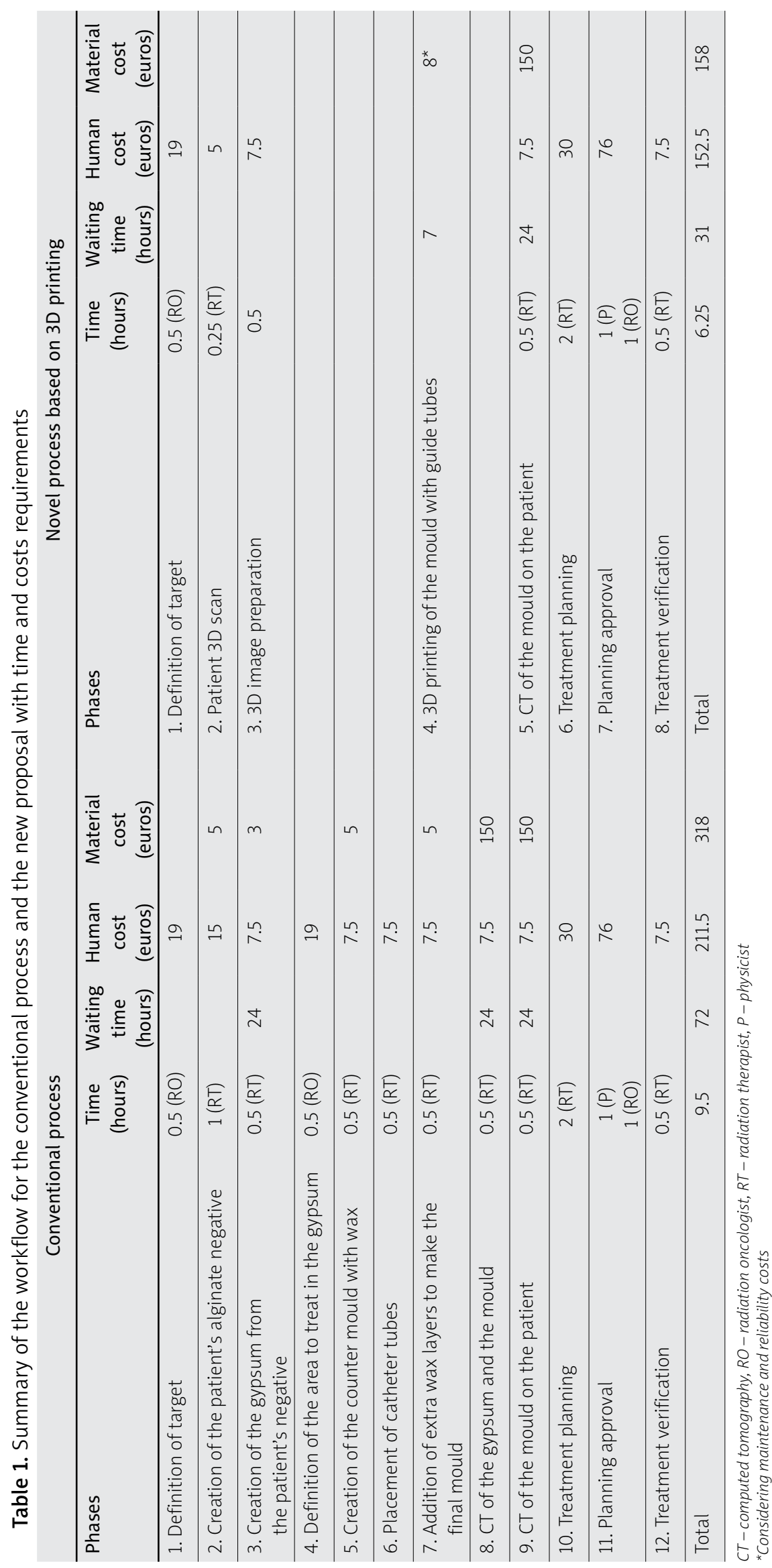


Table 2. Analysis of the cost of 3D printing a mould of a patient, printed at $90 \%$ infill and weighing 94 gram (taking 7 hours)

\begin{tabular}{|c|c|c|c|}
\hline Phases & Unit cost & Cost per hour (euros) & Total cost (euros) \\
\hline $\begin{array}{l}\text { 3D printer (considering workflow of } 60 \text { patients per year } \\
\text { and over a period of } 6 \text { years) }\end{array}$ & $1,800-2,300 €$ & $0.71-0.91$ & $4.97-6.37$ \\
\hline PLA spool & $20.80 € / \mathrm{kg}$ & & 1.96 \\
\hline Disposables & & & 0.1 \\
\hline Electricity (240 Watts) & $0.16 € / \mathrm{kWh}$ & & 0.27 \\
\hline Repair cost (about $10 \%$ of purchase cost over the 6 years) & $180-230 €$ & 0.07-0.09 & $0.5-0.64$ \\
\hline Software & 0 & 0 & 0 \\
\hline Subtotal & & & $7.8-9.34$ \\
\hline Failed moulds (considering a $15 \%$ failure) & & & $1.17-1.4$ \\
\hline Total & & & $8.97-10.74$ \\
\hline
\end{tabular}

Note: Printers costing as little as 1,800 € can offer the same reliability as the printer currently used in this study, which cost 2,300 €. The low-high figures in this example reflects the price difference.

The mould that is created by 3D printing offers a reduction in time taken to make the mould and a reduction in material costs. In spite of the modest time saving, the new workflow gives the opportunity to measure the $3 \mathrm{D}$ surface of the patient, who can be in the general practitioner's office or in satellite units belonging to the hospital network. We are currently actively working on this area [34]. The use of modelling software allows for a quicker and automated creation of radiotherapy complements. The costs have been calculated based on the fact that the Spanish regulations state that only materials for medical use must have a certificate. Surface scanner and 3D printers do not need any special certification. National variations in regulations might alter costs. Both maintenance, reliability, and electricity costs have been included in the printing price calculated, taking into account a flow of 60 patients per year, which is the current demand in our hospital. The proportional depreciation cost of the printer will be lower in those centers with a higher need, as will the cost of each printing job. For the calculations, a minimum operating period of six years and a failure rate of $15 \%$ were considered.

Our goal is to maintain only 2 workflows in the Department for this type of patient. The first, addressing largely irregular areas or places with important aesthetic issues, like the face, will involve the 3D printing technique. The second, addressing flat area with lesser aesthetic importance, will continue with standard, re-usable, and cheaper moulds. The reason for this difference lies in the fact that the re-usable moulds have drawbacks like the creation of air pockets between curved skin surfaces and the moulds.

Obviously, implementation and standardization of the 3D printing technique depends on the number of patients that might benefit in each radiation department.

All tests have been carried out for small to mediumsized areas. However, the only limitation is the size of the printer. As long as the area is small enough to fit onto the printer platform (in our case is $21 \times 30 \times 21 \mathrm{~cm}$ ), any size moulds can be printed. Moulds that are too big can be created in parts and assembled later. No minimum size is required, as long as it covers the affected area. Once obtained, the 3D model can be adapted, and a mould bigger than the affected area can be printed in order to comfortably fit the patient's skin, regardless of the dimensions of the tumor. For example, for a nasal lesion, the printed mould can extend from between the eyebrows to the mouth in order to fit all the area properly.

We suggest the new process will be well received among the brachytherapy community, patients, and professionals alike (radiation oncologists, physicists, radiation therapists). It is an alternative therapeutic technique that reduces workload and saves time, allowing patients to move into treatments much sooner. More complex moulds can be created by machine rather than by hand thus reducing the possibility of human error.

3D printing improves reproducibility of the mould, as well as its quality and durability, meaning better overall quality [35]. The consistency of the tube placement $(1 \mathrm{~cm}$ apart and $5 \mathrm{~mm}$ from the skin) will provide dosimetric advantages. The position and number of catheters can be defined before the mould is actually constructed, based on the patient's CT data. Thus, optimization plan might include the number and position of the catheters, which would provide dosimetrically superior treatment plans. However, we are currently at the preliminary stage, in which we are validating whether the method can be applied. Incorporation of the mould design in the optimization process is still in progress, and will be addressed in the future. The final step, not yet reached in our department, is to create a complete inverse planning from the skin surface scanning to the optimal tube placement and the final mould creation, according to the previous steps. These personalized approaches could be adapted to other radiotherapy fields such as breast cancer [36].

The discomfort caused by the creation of the patients' negative might be subjective and be interpreted differently, but we think the proposed process, which only requires the use of a contactless surface scanner on the 
patient, is much less intrusive and faster than the conventional process. Although no formal tests were given to patients, they reported discomfort, especially when nose and eyes had to be included in the gypsum working area. The new process will cause less discomfort to the patient.

\section{Conclusions}

$3 \mathrm{D}$ printing is a promising technique for brachytherapy. It offers financial advantages, a reduction in the clinical workload, and less discomfort to patients. However, before being implemented into clinical practice, future work is needed to validate dosimetry and to characterize the printing material.

\section{Acknowledgements}

We are indebted to "Associació Oncològica Dr Amadeu Pelegrí" for their financial support in this current research. Thanks to Mr. Phil Hoddy, who corrected and edited the English text.

\section{Disclosure}

The study was supported by research grant from "Associació Oncològica Dr Amadeu Pelegrí".

\section{References}

1. Sabater S, Pastor-Juan Mdel R, Berenguer R et al. Analysing the integration of MR images acquired in a non-radiotherapy treatment position into the radiotherapy workflow using deformable and rigid registration. Radioth Oncol 2016; 119: 179-184.

2. Rengier F, Mehndiratta A, von Tengg-Kobligk $H$ et al. 3D printing based on imaging data: review of medical applications. Int J Comput Assist Radiol Surg 2010; 5: 335-341.

3. Malik HH, Darwood AR, Shaunak S et al. Three-dimensional printing in surgery: a review of current surgical applications. J Surg Res 2015; 199: 512-522.

4. Su S, Moran K, Robar JL. Design and production of 3D printed bolus for electron radiation therapy. J Appl Clin Med Phys 2014; 15: 4831.

5. Kim SW, Shin HJ, Kay CS et al. A customized bolus produced using a 3-dimensional printer for radiotherapy. PLoS One 2014; 9: e110746.

6. Zou W, Fisher T, Zhang M et al. Potential of 3D printing technologies for fabrication of electron bolus and proton compensators. J Appl Clin Med Phys 2015; 16: 4959.

7. Burleson S, Baker J, Hsia AT et al. Use of 3D printers to create a patient-specific 3D bolus for external beam therapy. J Appl Clin Med Phys 2015; 16: 5247.

8. Park JW, Yea JW. Three-dimensional customized bolus for intensity-modulated radiotherapy in a patient with Kimura's disease involving the auricle. Cancer Radiother 2016; 20 205-209.

9. Canters RA, Lips IM, Wendling M et al. Clinical implementation of $3 \mathrm{D}$ printing in the construction of patient specific bolus for electron beam radiotherapy for non-melanoma skin cancer. Radioth Oncol 2016; 121: 148-153.

10. Gear JI, Long C, Rushforth D et al. Development of patient-specific molecular imaging phantoms using a 3D printer. Med Phys 2014; 41: 082502.
11. Ehler ED, Barney BM, Higgins PD et al. Patient specific 3D printed phantom for IMRT quality assurance. Phys Med Biol 2014; 59: 5763-5773.

12. Bieniosek MF, Lee BJ, Levin CS. Technical Note: Characterization of custom 3D printed multimodality imaging phantoms. Med Phys 2015; 42: 5913-5918.

13. Madamesila J, McGeachy P, Villarreal Barajas JE et al. Characterizing $3 \mathrm{D}$ printing in the fabrication of variable density phantoms for quality assurance of radiotherapy. Phys Med 2016; 32: 242-247.

14. Avelino SR, Silva LF, Miosso CJ. Use of 3D-printers to create intensity-modulated radiotherapy compensator blocks. Conf Proc IEEE Eng Med Biol Soc 2012; 2012: 5718-5721.

15. Ju SG, Kim MK, Hong CS et al. New technique for developing a proton range compensator with use of a 3-dimensional printer. Int J Radiat Oncol Biol Phys 2014; 88: 453-458.

16. Cunha JA, Mellis K, Sethi R et al. Evaluation of PC-ISO for customized, 3D Printed, gynecologic 192-Ir HDR brachytherapy applicators. J Appl Clin Med Phys 2015; 16: 5168.

17. Sethi R, Cunha A, Mellis K et al. Clinical applications of custom-made vaginal cylinders constructed using three-dimensional printing technology. J Contemp Brachytherapy 2016; 8: 208-214.

18. Lindegaard JC, Madsen ML, Traberg A et al. Individualised 3D printed vaginal template for MRI guided brachytherapy in locally advanced cervical cancer. Radiother Oncol 2016; 118: 173-175.

19. Harris BD, Nilsson S, Poole CM. A feasibility study for using ABS plastic and a low-cost 3D printer for patient-specific brachytherapy mould design. Australas Phys Eng Sci Med 2015; 38: 399-412.

20. Poulin E, Gardi L, Fenster A et al. Towards real-time 3D ultrasound planning and personalized 3D printing for breast HDR brachytherapy treatment. Radioth Oncol 2015; 114: 335-338.

21. Ricotti R, Vavassori A, Bazani A et al. 3D-printed applicators for high dose rate brachytherapy: dosimetric assessment at different infill percentage. Phys Med 2016; 32: 1698-1706.

22. Jones EL, Tonino Baldion A, Thomas C et al. Introduction of novel 3D-printed superficial applicators for high-dose rate skin brachytherapy. Brachytherapy 2017; 16: 409-414.

23. Bath-Hextall F, Leonardi-Bee J, Smith $\mathrm{C}$ et al. Trends in incidence of skin basal cell carcinoma. Additional evidence from a UK primary care database study. Int J Cancer 2007; 121: 2105-2108.

24. Neville JA, Welch E, Leffell DJ. Management of nonmelanoma skin cancer in 2007. Nat Clin Pract Oncol 2007; 4: 462-469.

25. Arenas M, Arguis M, Diez-Presa L et al. Hypofractionated high-dose-rate plesiotherapy in nonmelanoma skin cancer treatment. Brachytherapy 2015; 14: 859-865.

26. Skowronek J. Brachytherapy in the treatment of skin cancer: an overview. Postepy Dermatol Alergol 2015; 32: 362-367.

27. Delishaj D, Laliscia C, Manfredi B et al. Non-melanoma skin cancer treated with high-dose-rate brachytherapy and Valencia applicator in elderly patients: a retrospective case series. J Contemp Brachytherapy 2015; 7: 437-444.

28. Delishaj D, Rembielak A, Manfredi B et al. Non-melanoma skin cancer treated with high-dose-rate brachytherapy: a review of literature. J Contemp Brachytherapy 2016; 8: 533-540.

29. Haseltine JM, Parker M, Wernicke AG et al. Clinical comparison of brachytherapy versus hypofractionated external beam radiation versus standard fractionation external beam radiation for non-melanomatous skin cancers. J Contemp Brachytherapy 2016; 8: 191-196.

30. Villalba SR, Perez-Calatayud MJ, Bautista JA et al. Novel simple templates for reproducible positioning of skin applicators in brachytherapy. J Contemp Brachytherapy 2016; 8: 344-348. 
31. Kuncman Ł, Kozłowski S, Pietraszek A et al. Highly conformal CT based surface mould brachytherapy for non-melanoma skin cancers of earlobe and nose. J Contemp Brachytherapy 2016; 8: 195-200.

32. Ballester-Sanchez R, Pons-Llanas O, Candela-Juan C et al. Electronic brachytherapy for superficial and nodular basal cell carcinoma: a report of two prospective pilot trials using different doses. J Contemp Brachytherapy 2016; 8: 48-55.

33. Ballester-Sanchez R, Pons-Llanas O, Candela-Juan C et al. Efficacy and safety of electronic brachytherapy for superficial and nodular basal cell carcinoma. J Contemp Brachytherapy 2015; 7: 231-238.

34. Arenas M, Gomez D, Sabater S et al. Decentralisation of radiation therapy. Is it possible and beneficial to patients? Experience of the first 5 years of a satellite radiotherapy unit in the province of Tarragona, Spain. Rep Pract Oncol Radiother 2014; 20: 141-144.

35. Arenas M, Sabater S, Gascon M et al. Quality assurance in radiotherapy: analysis of the causes of not starting or early radiotherapy withdrawal. Radiat Oncol 2014; 9: 260.

36. Arenas M, Hernandez V, Farrus B et al. Do breast cups improve breast cancer dosimetry? A comparative study for patients with large or pendulous breasts. Acta Oncol 2014; 53: 795-801. 